\title{
Paradigm shift needed for cervical cancer: HPV infection is the real epidemic
}

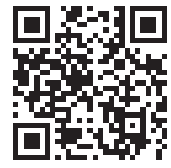

Thirty years ago the now Nobel Prize winner Harald Zur Hausen first described high-risk human papillomavirus (hrHPV) type 16 in cervical cancer specimens (Fig. 1). Since then, hrHPV infection has been established as a prerequisite for the development of cervical cancer. Cervical cancer prevention programmes in many developed countries already include primary prevention through immunisation against hrHPV types 16 and 18 before hrHPV exposure, combined with secondary prevention via cytology-based screening, often augmented by testing for hrHPV infection. The benefit of acquired knowledge and new technologies must now be extended to developing countries, where $85 \%$ of deaths attributable to cervical cancer occur.

In South Africa (SA) the prevalence of this preventable cancer is alarmingly high, presentation is late and survival rates are poor, in spite of excellent treatment available at most tertiary facilities. The unfortunate underlying reasons include opportunistic and variably implemented cytology-based screening ${ }^{[1]}$ and a poorly controlled human immunodeficiency virus (HIV) epidemic with high HIV prevalence, late diagnosis and incomplete access to timely treatment. The effect of HIV co-infection on the prevalence and natural history of HPV infection and associated disease is well described in the literature $^{[2]}$ and seen by gynaecological oncologists in SA (Fig. 2).

Cervical cancer and infectious disease experts in SA have discussed the causes of and potential solutions to this epidemic for several years. After consideration of the available evidence, a group of local experts published guidelines for the implementation of primary screening with hrHPV testing in 2005, with an update in 2010. ${ }^{[3]}$ These guidelines were among the first in the world to acknowledge the potential of hrHPV molecular tests in primary screening, and also proposed self-sampling. An hrHPV-based screening cost-effectiveness analysis $^{[4]}$ and clinical guidelines for HPV vaccine implementation in SA were also published. ${ }^{[5]}$ Unfortunately, uptake of HPV vaccination has been slow ${ }^{[6]}$ and populationbased screening remains only partially implemented. ${ }^{[1]}$

In this issue of SAMJ, Moodley et al. report the outcome of a vaccine demonstration project in rural KwaZulu-Natal $(\mathrm{KZN}){ }^{[7]}$
Almost all the girls who had parental consent and therefore met the inclusion criteria received the first dose of vaccine, and the completion rate of $97.8 \%$ was impressive. It is important to demonstrate effective vaccine delivery in SA schools, and these results will assist in planning larger vaccine projects. Among the lessons learnt, the authors mention various aspects of administration and training, communication and team involvement. The authors, co-workers and sponsors must be commended for the huge effort and successful completion of this trial. To reach a high uptake in this study, information and motivation of all stakeholders and proper communication with schools, teachers, parents, girls and their communities were ensured and were

\begin{tabular}{|ll|}
\hline 1928 & Georgios Papanicolaou developed the Papanicolaou technique \\
1941 & First'Pap smear' screening technique developed \\
1949 & First mass 'Pap smear'screening \\
1949 & HPV seen on an electron microscope \\
1963 & HPV DNA identified \\
1976 & Harald Zur Hausen found HPV DNA in cervical cancer and warts \\
1983 & Harald Zur Hausen identifies HPV type 16 in cervical cancer \\
1984 & Harald Zur Hausen identifies HPV type 18 in cervical cancer \\
1988 & Bethesda System for reporting 'Pap smear' results developed \\
2003 & First HPV-based cervical cancer screening test FDA approved \\
2006 & First HPV vaccine, Gardasil (Merck), approved by the FDA \\
2007 & Second HPV vaccine, Cervarix (GSK), approved by the FDA \\
2008 & Gardasil and Cervarix approved by the MCC in South Africa \\
\hline
\end{tabular}

Fig. 1. The history of cervical cancer prevention and human papillomavirus (FDA = US Food and Drug Administration; $M C C=$ Medicines Control Council).

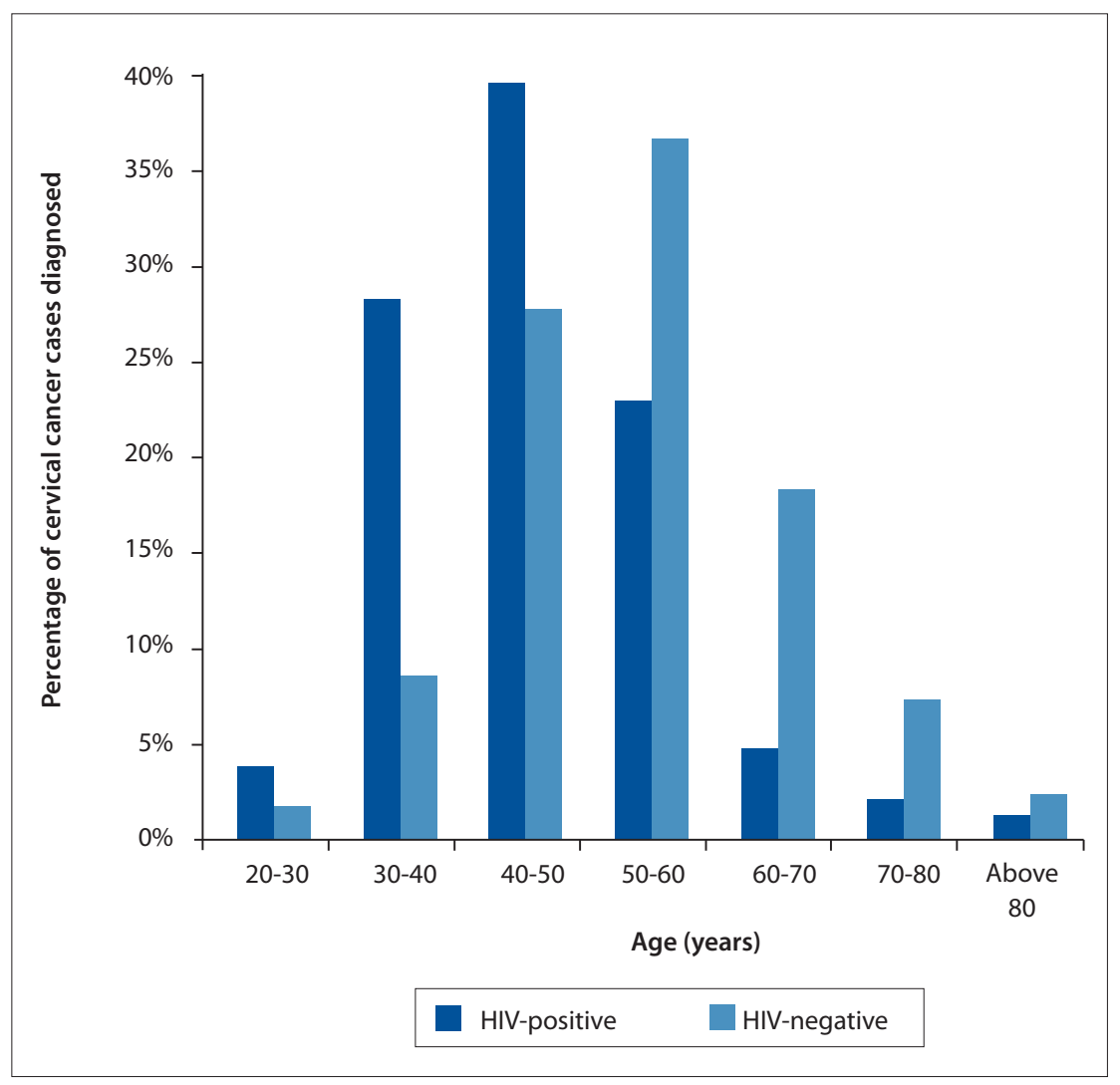

Fig. 2. Age at presentation of women with invasive cervical cancer (unpublished data, University of Pretoria Gynaecological Oncology Unit, 2011). 


\section{EDITORIALS}

thought to be critical. Apart from the uptake of the vaccine, costeffectiveness of a national HPV vaccination programme will be determined by the burden of disease, vaccine pricing, number of doses administered, viral types covered (both vaccine types and cross-protection), and cost of the vaccination process.

The hrHPV prevalence among a large sample of SA women reported by Richter et al. in this issue of $S A M J$ is cause for alarm, although these results cannot be generalised to all women in sub-Saharan Africa. ${ }^{[8]}$ This study, performed among women attending public sector primary healthcare clinics in the Tshwane area of Gauteng, describes the highest prevalence of hrHPV ever reported in an unselected screening population (Fig. 3). Importantly, the age distribution shows a unique plateau-like curve without the expected decline of HPV infection from age 30 and older. The risk factors associated with increased HPV infection rates were not studied in this trial, but are well known. ${ }^{[2,9]}$ In addition, the reported prevalence of high-grade intraepithelial lesions (HSIL) or worse on cytology is near $10 \%$. This unprecedented high prevalence on a single round of cytology testing correlates with extremely high prevalences of HPV types 16 and/or 18 (near 20\%) and hrHPV overall (over 50\%), as well as with the high prevalence and young age at presentation of women with invasive cervical cancer. Cervical cancer is the leading cause of cancer death in women in southern Africa, despite being one of the most preventable of all malignancies. The high burden of disease demonstrated in this study underlines the importance and urgency of HPV vaccination and screening in SA, and indicates a high expected return on investment.

Implementing HPV vaccination. Although too late for women who are already infected, the commercial launch of two vaccines against HPV in 2006 and 2007 meant that future generations of women can go into their sexually active years protected from HPV types 16 and 18, which cause $60-70 \%$ of cervical cancers. Remaining hurdles include the cost and complexity of the implementation process. Vaccination systems that can ensure a high uptake and deliver all doses within a 6-month period in a school-based programme are needed. Effective

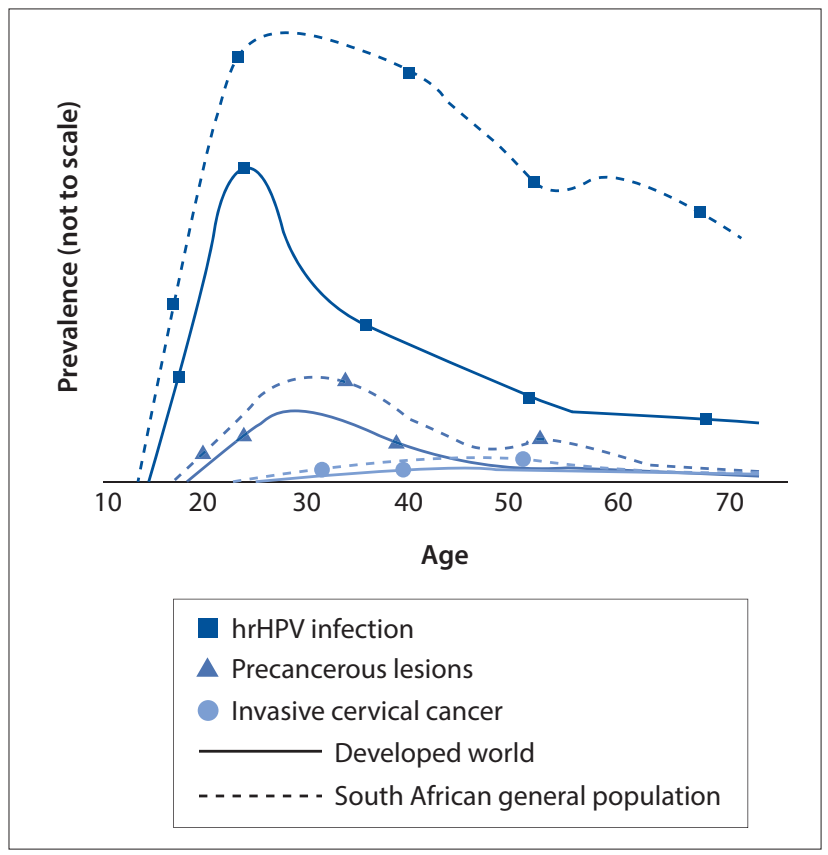

Fig. 3. Age-related prevalence of human papillomavirus infections, (squares), pre-cancerous lesions (triangles), and cervical cancer (circles) as traditionally described in the developed world (solid lines) ${ }^{[9]}$ and in the general South African population (dashed lines), as described by Richter et al ${ }^{[8]}$ and unpublished data from the University of Pretoria Gynaecological Oncology Unit (2011). The figure shows trends and prevalence relative to each other rather than the absolute prevalence, so there is no vertical axis.

\begin{tabular}{|c|c|c|c|c|c|c|c|c|c|c|c|c|c|c|c|c|c|c|c|c|}
\hline \multirow{2}{*}{ 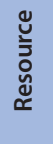 } & \multirow{2}{*}{ 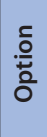 } & \multirow{2}{*}{ Description } & \multicolumn{18}{|c|}{ Age (years) } \\
\hline & & & 10 & 20 & & & 30 & & & 40 & & & & 50 & & & 60 & & & 70 \\
\hline \multirow{3}{*}{ 䱏 } & A & $\begin{array}{l}\text { Established cytology- } \\
\text { based screening }\end{array}$ & & C & C & $C$ & C & C & C & C & $C$ & C & $C$ & C & C & C & $C$ & C & C & \\
\hline & B & $\begin{array}{l}\text { Current screening by } \\
\text { co-testing }\end{array}$ & & c & c & C & $\begin{array}{l}\mathrm{C} \\
\mathrm{H}\end{array}$ & $\begin{array}{l}\mathrm{C} \\
\mathrm{H}\end{array}$ & $\begin{array}{l}\mathrm{C} \\
\mathrm{H}\end{array}$ & \begin{tabular}{l|l}
$\mathrm{C}$ & $\mathrm{C}$ \\
$\mathrm{H}$ & $\mathrm{H}$
\end{tabular} & $\begin{array}{l}\mathrm{C} \\
\mathrm{H}\end{array}$ & $\begin{array}{l}\mathrm{C} \\
\mathrm{H}\end{array}$ & $\begin{array}{l}\mathrm{C} \\
\mathrm{H}\end{array}$ & $\begin{array}{l}\mathrm{C} \\
\mathrm{H}\end{array}$ & $\begin{array}{l}\mathrm{C} \\
\mathrm{H}\end{array}$ & $\begin{array}{l}\mathrm{C} \\
\mathrm{H}\end{array}$ & $\begin{array}{l}\mathrm{C} \\
\mathrm{H}\end{array}$ & $\begin{array}{l}\mathrm{C} \\
\mathrm{H}\end{array}$ & \begin{tabular}{|l}
$\mathrm{C}$ \\
$\mathrm{H}$
\end{tabular} & \\
\hline & C & $\begin{array}{l}\text { Proposed screening } \\
\text { in vaccinated cohorts }\end{array}$ & V & & & & $\mathrm{H}$ & & -1 & $\mathrm{H}$ & & $\mathrm{H}$ & & $\mathrm{H}$ & $\mathrm{H}$ & & $\mathrm{H}$ & & $\mathrm{H}$ & \\
\hline \multirow{2}{*}{$\begin{array}{l}\frac{\xi}{\bar{z}} \\
\frac{\bar{z}}{\overline{0}} \\
\sum\end{array}$} & D & $\begin{array}{l}\text { SA: Current cytology- } \\
\text { based screening }\end{array}$ & & & & & C & & & c & & & & c & & & c & & & \\
\hline & E & $\begin{array}{l}\text { SA: Proposed HPV- } \\
\text { based prevention }\end{array}$ & V & & & & $\mathrm{H}$ & & & $\mathrm{H}$ & & & & $\mathrm{H}$ & & & $\mathrm{h}$ & & & \\
\hline ô & $F$ & Minimum screening & $\pm v$ & & & & & & & /C/V & & & & & & & & & & \\
\hline
\end{tabular}

Fig. 4. Cervical cancer prevention strategies in different patient populations. Current or proposed screening options integrating cytology, HPV testing, visual inspection and HPV vaccination in high-resourced, ${ }^{[12,14]}$ middle-resourced and low-resourced settings ${ }^{[15-17]}$ are displayed (SA $=$ South Africa; HPV $=$ human papillomavirus; $V=H P V$ vaccination; $C=$ cytology-based screening; $H=h r H P V$-based screening; $c=$ cytology-based screening if not previously screened; $h=h r H P V-b a s e d$ screening if not previously screened; VI = visual inspection-based screening). 
vaccine delivery with high uptake in the school setting has been demonstrated in KZN, Gauteng and the Western Cape. ${ }^{[7,10,11]}$

Implementing HPV-based screening. Mortality from cervical cancer in developed countries is low because of the availability of prevention by early detection of risk, followed by effective treatment. These successes have never been mirrored in the developing world. Cervical cancer mortality can be substantially lowered with any screening test, provided that the necessary coverage, screening interval, follow-up and treatment of screen-positive individuals can be guaranteed. The cost-effectiveness, sensitivity and specificity of the different tests and screening intervals are, however, very different. HrHPV-based screening tests offer several advantages over cytologybased tests. These include increased clinical sensitivity and excellent negative predictive value. Screening intervals can therefore safely be increased. Women can self-collect samples, which will relieve healthcare personnel. Although evaluating this was not the primary aim of the study by Richter et al., willingness of women to self-collect in a subset of the study population is encouraging. HPV-based tests are also amenable to high-throughput automated laboratory testing as opposed to labour-intensive manual cytology screening.

Proposed cervical cancer prevention model for South Africa. The question arises: what is the optimal cervical cancer prevention programme for a middle-resourced country with an extremely high burden of HPV-associated disease like SA? Owing to limited resources, we cannot afford a 'catch-all' strategy and will have to optimise the cost-effectiveness of the preventive programme. Different cervical cancer prevention strategies and the proposed model for SA are outlined in Fig. 4. An ideal cervical cancer control programme should emphasise HPV vaccination before average age at first sexual intercourse, combined with appropriately spaced hrHPV testing for primary screening, starting at age 30 years in immunocompeten women (option C). ${ }^{[12]}$ Vaccine coverage must first be directed where it will have the greatest impact. Although the case can be made for catch-up vaccination of adult women, and boys, the initial target should therefore be girls before their sexual debut. It is widely accepted that HPV vaccination should be primary school based.

Universal vaccination of young girls is only expected to start to result in a decrease in cervical cancer incidence after two decades. Screening will remain essential for unvaccinated women and to screen for cancers caused by non-vaccine types in vaccinated women. Modern assays provide good choices for lower-resourced settings with a high HPV prevalence, enabling prioritisation of women at highest risk of cancer while maintaining the excellent sensitivity that allows a longer screening interval. While earlier hrHPV DNAbased tests needed an additional triage test to improve specificity and predictive value, newer tests are designed for screening and combine high sensitivity with increased clinical specificity. This is accomplished by partial hrHPV DNA genotyping and calibration against risk for clinically relevant disease, or by type-specific testing for mRNA expression of the HPV oncogenes E6 and E7. ${ }^{[13,14]}$

Experts agree that the current emphasis on repeated cytology screening as in established programmes (option A) is inefficient. Most new proposals call for less frequent but more sensitive screening that incorporates testing for hrHPV. ${ }^{[1,14]}$ For developed settings, co-testing has been proposed (option B), ${ }^{[1,1,14]}$ but such a strategy is highly resource intensive and reflects fear of litigation. In contrast, the World Health Organization suggests a minimum of screening at least a once in a lifetime between the ages of 35 and 45 years for the lowest-resourced settings (option F) ${ }^{[15]}$ This screening can be visual inspection based (lowest accuracy), cytology based (low sensitivity) or HPV based (high sensitivity), as demonstrated in India ${ }^{[16]}$ and in SA. ${ }^{[17]}$

We propose initiation of primary school-based HPV vaccination as soon as possible, as well as 10-yearly HPV-based screening (option E), combined with effective treatment of women with positive screening tests. This strategy will provide a major advancement in cervical cancer prevention when compared with the current inefficient cytology guidelines for SA (option D). Vaccination and screening programmes should focus on the least-serviced communities first. HPV vaccination and adequately implemented hrHPV-based screening in SA can save the lives of many women.

\section{K Richter}

Department of Medical Virology, University of Pretoria and National Health Laboratory Service, Tshwane Academic Division, South Africa

\section{G Dreyer}

Gynaecological Oncology Unit, Department of Obstetrics and Gynaecology, Pretoria Academic Hospital Complex and University of Pretoria, South Africa

\section{Corresponding author: KRichter (karin.richter@up.ac.za)}

1. Denny L. Prevention of cervical cancer. Reprod Health Matters 2008;16(32):18-31. [http://dx.do org/10.1016/S0968-8080(08)32397-0

. Palefsky J. Human papillomavirus-related disease in people with HIV. Curr Opin HIV AID 2009;4(1):52-56. [http://dx.doi.org/10.1097/COH.0b013e32831a7246

3. South African HPV Advisory Board. Cervical cancer and human papillomavirus: South African guidelines for screening and testing. South African Journal of Gynaecological Oncology 2010;2(1):23 26. www.sasog.co.za/images/Guidelines.pdf (accessed 4 April 2013).

4. Vijayaraghavan A, Efrusy M, Lindeque G, et al. Cost effectiveness of high-risk HPV DNA testin for cervical cancer screening in South Africa. Gynecol Oncol 2009;112(2):377-383. [http://dx.dol. org/10.1016/j.ygyno.2008.08.030]

5. South African HPV Advisory Board. Prophylactic human papillomavirus vaccination against cervica cancer: A summarised resource for clinicians. South African Journal of Gynaecological Oncolog 2011;3(1):39-42. http://www.sajgo.co.za/index.php/sajgo/article/view/60/pdf_23 (accessed 4 Apri 2013)

6. Allie N, Moodley M. Knowledge, awareness and utilisation of the human papillomavirus vaccine in Durban. South African Journal of Gynaecological Oncology 2012;4(1):6-10. http://www.sajgo.co.za/ index.php/sajgo/article/view/86/pdf_1 (accessed 8 April 2013).

7. Moodley I, Tathiah N, Mubaiwa V, et al. High uptake of Gardasil vaccine among 9 - 12-year-old schoolgirls participating in an HPV vaccination demonstration project in KwaZulu-Natal, South Africa. S Afr Med J 2013;103(5):318-321. [http://dx.doi.org/10.7196/SAMJ.6414]

8. Richter K, Becker P, Horton A, Dreyer G. Age-specific prevalence of cervical human papillomaviru infection and cytological abnormalities in women in Gauteng province, South Africa. S Afr Med 2013;103(5):313-317. [http://dx.doi.org/10.7196/SAMJ.6514]

9. Schiffman M, Gage IC, Clarke MA. Accepting the universal truths of cervical human papillomavirus epidemiology in pursuit of the remaining mysteries. Sex Transm Dis 2011;38(10):907-908. [http:/ dx.doi.org/10.1097/OLQ.0b013e318224a63f

10. Botha MH, van der Merwe FH, Snyman LC, Dreyer G. Vaccine and cervical cancer screen project (13-16 October 2012, Vancouver, Canada.

11. Dreyer G, Snyman L, Burden R, et al. The 'VACCS' trial: First interim analysis of the vaccine and cervical cancer screen project. Presented at the AOGIN congress, 13 July 2012, Hong Kong, Peoples Republic of China.

12. Schiffman $\mathrm{M}$, Wentzensen $\mathrm{N}$, Wacholder $\mathrm{S}$, et al. Human papillomavirus testing in the prevention of cervical cancer. J Natl Cancer Inst 2011;103(5):368-383. [http://dx.doi.org/10.1093/jnci/djq562]

13. Cuzick I, Cadman L, Mesher D, et al. Comparing the performance of six human papillomavirus test in a screening population. Br J Cancer 2013;108(4):908-913. [http://dx.doi.org/10.1038/bjc.2013.22]

14. Jin XW, Lipold L, McKenzie M, Sikon A. Cervical cancer screening: What's new and what's coming? Cleveland Clinic J Med 2013;80(3):153-160. [http://dx.doi.org/10.3949/ccim.80a.12092]

15. World Health Organization. Comprehensive Cervical Cancer Control: A Guide to Essential Practice. Geneva: WHO Press, 2006. http://www.who.int/reproductivehealth/publications/cancers/9241547006/ en/index.html (accessed 28 March 2013).

16. Sankaranarayanan R, Nene BM, Shastri SS, et al. HPV screening for cervical cancer in rural India. $N$ Engl J Med 2009;360(14):1385-1394. [http://dx.doi.org/10.1097/COH.0b013e32831a7246]

17. Denny L, Kuhn L, Hu C, et al. Human papillomavirus-based cervical cancer prevention: Long-term results of a randomized screening trial. I Natl Cancer Inst 2010;102(20):1557-1567. [http//dedol org/10.1093/inci/djq342]

S Afr Med J 2012;103(5):290-292. DOI:10.7196/SAMJ.6936 